\title{
Theoretical Modelling of Plate with Attached Vibration Absorber
}

\section{Izzuddin Zaman 1,2,a , Muhammad Mohamed Salleh", Bukhari Manshoor ${ }^{1}$, Amir Khalid ${ }^{1}$, Mohd Zamani Ngali ${ }^{1}$ and Mohd Shahrir Mohd Sani ${ }^{3}$}

${ }^{1}$ Faculty of Mechanical and Manufacturing Engineering, ${ }^{2}$ Structural Integrity and Monitoring Research Group, Universiti Tun Hussein Onn Malaysia, 86400 Batu Pahat, Johor, Malaysia

${ }^{3}$ Faculty of Mechanical Engineering, Universiti Malaysia Pahang, 26600 Pekan, Pahang, Malaysia

aizzuddin@uthm.edu.my

Keywords: Fixed-fixed ends plate, vibration control, vibration absorber, mathematical model

Abstract. There are many ways to control the vibration of plate structure. Conventional approaches that include structural alterations are frequently time consuming and costly. One of the common schemes is using vibration absorber attached to a structure. In this paper, a mathematical model is developed to determine the frequency response of fixed-fixed ends plate with attached vibration absorber. A finite element analysis was performed and compared with the theoretical predictions and showed that there was good resemblance. The results demonstrated that the addition of vibration absorber onto plate can attenuate vibration considerably at a constant frequency.

\section{Introduction}

One of the most commonly used structures in the industrial is plate. The structural elements of plate are originally flat having a thickness smaller than the sides' dimensions. Plate evolves shear forces, bending and twisting moments to resist transverse loads, and typically they are stiffer than a beam of comparable span and thickness [1]. Thus, thin plates combine with lightweight are certainly offers economy advantages and technological effectiveness. Because of that, plates are extensively being utilized in numerous applications such as aviations, machinery, vehicles, instruments, computer peripherals and modern houses. Fig. 1 shows some of the examples of the application of plate.

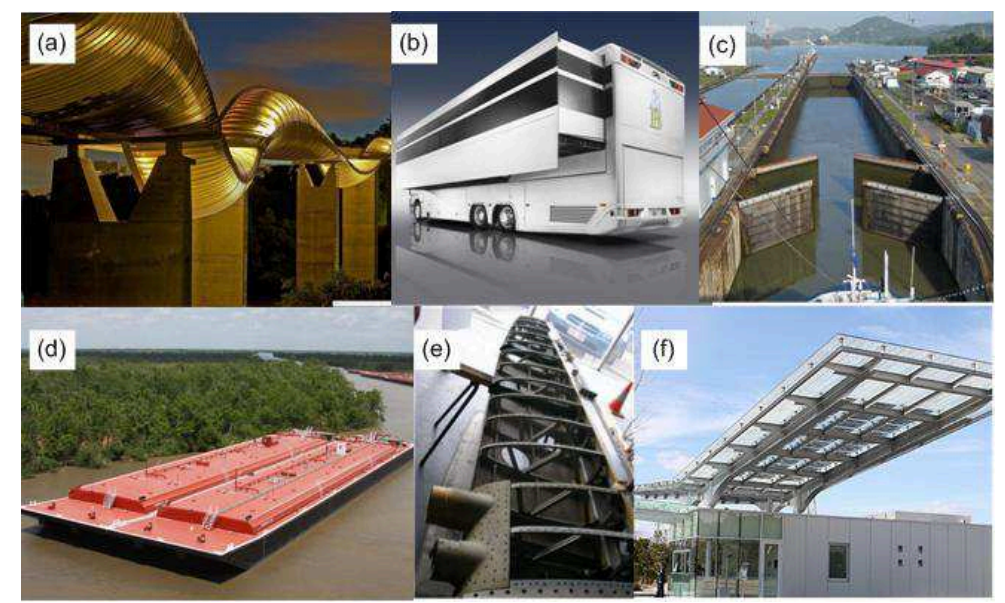

Fig. 1. Potential of plate's applications

Vibrations on the other hand are always undesirable, wasting energy and producing noise [2,3]. In this case, plates which are prominent component in most of engineering fields having no exemption from the vibration effect when a structure imposed by dynamic loading. One of the traditional treatment method involves structural modification, such as adding ribs and damping $[4,5]$. However, this method is not effective due to its design complexity and expensive. This in turn cultivates a new idea of installation of vibration absorbers, which are more promising as they do not contribute significant additional energy to the structure [6-8]. The work presented in this paper describes the frequency response of fixed-fixed ends plate with attached a vibration absorber. This 
includes details derivation of mathematical equations of plate with and without attached vibration absorber, in which the authors were unable to discover in the literature [8,9]. Albeit the work displayed in the paper was a "work in progress", yet it did present some promising result that well corroborated with simulation result. The authors hope that the theoretical derivation demonstrated in this paper provide a helpful reference to future researchers who endeavor to find an equation for fixed-fixed ends plate with attached vibration absorber.

\section{Theoretical Equations}

This section describes the derivation of a mathematical model which allows the calculation of frequency response function of fixed-fixed ends plate with attached a vibration absorber. At first, the mathematical equation for structural behavior of fixed-fixed ends plate is derived, which is then followed by the addition of absorber.

Vibration response of fixed-fixed ends plate. Consider a three dimensional plate with dimensions $a, b$ and $c$ which represent length, width and thickness subjected to a vertical point load $F$. The equation of motion of a plate can be written as in Eq. 1 [10]:

$$
E I\left(\frac{\partial^{4} w}{\partial x^{4}}+2 \frac{\partial^{2} w}{\partial x^{2} \partial y^{2}}+\frac{\partial^{4} w}{\partial y^{4}}\right)+\rho h \frac{\partial^{2} w}{\partial t^{2}}=-F\left(x_{i}, y_{i}, t\right)
$$

where $E$ is the Young's modulus, $I$ is the area moment of inertia, $\rho$ is the density of plate and $h$ is thickness of plate. The area moment of inertia for plate is defined as in Eq. 2, where $v$ is the Poisson's ratio.

The solution of transverse modal displacement for a plate is given in Eq. 3 which is summation of all of the individual modal amplitude responses multiplied by their mode shapes at that point [8].

$$
w(x, y, t)=\sum_{m=1}^{\infty} \sum_{n=1}^{\infty} W_{m n} \cdot \psi_{m n}(x, y) e^{j \omega_{n} t}
$$

where $W_{m n}$ is the modal amplitude, $\psi_{m n}(x, y)$ is the mode shape of plate, and $m$ and $n$ are modal integers. The general mode shape of a fixed-fixed ends plate can be determined using Eq. 4, with two independent functions $X_{m}$ and $Y_{m}$ can be calculated from Eqs. 5 and 6, respectively.

$$
\begin{aligned}
& \psi_{m n}(x, y)=X_{m}(x) \cdot Y_{n}(y) \\
& X_{m}(x)=\cosh \left(k_{m n} x\right)-\cos \left(k_{m n} x\right)-\beta_{m n}\left[\sinh \left(k_{m n} x\right)-\sin \left(k_{m n} x\right)\right] \\
& X_{m}(x)=\cosh \left(k_{m n} x\right)-\cos \left(k_{m n} x\right)-\beta_{m n}\left[\sinh \left(k_{m n} x\right)-\sin \left(k_{m n} x\right)\right]
\end{aligned}
$$

where parameters $\beta_{m n}$ and $k_{m n}$ are obtained in the respective Eqs. 7 and 8.

$$
\begin{aligned}
& \beta_{m n}=\frac{\cosh \left(k_{m n} L\right)-\cos \left(k_{m n} L\right)}{\sinh \left(k_{m n} L\right)-\sin \left(k_{m n} L\right)} \\
& \cosh \left(k_{m n} L\right) \cdot \cos \left(k_{m n} L\right)-1=0
\end{aligned}
$$


The natural frequencies of a fixed-fixed ends plate can be calculated from Eq. 9 [10].

$$
\omega_{m n}=\sqrt{\frac{E I}{\rho h}} \cdot\left[\left(k_{m}\right)^{2}+\left(k_{n}\right)^{2}\right]
$$

Therefore from the derivation of Eqs. 3 to 9, by neglecting the exponential time varying term, an expression of the total response of fixed-fixed ends plate incorporating the viscous damping, $\zeta$ is simplified as in Eq. 10.

$$
w(x, y, t)=\frac{F}{\rho a b c} \sum_{m=1}^{\infty} \sum_{n=1}^{\infty} \frac{\psi_{m n}(x, y) \cdot \psi_{m n}\left(x_{i}, y_{i}\right)}{\omega_{m n}^{2}-\omega^{2}+j 2 \zeta \omega \omega_{m n}}
$$

Fixed-fixed ends plate with attached a vibration absorber. Consider a model of a fixed-fixed ends plate attached with a vibration absorber subjected by a harmonic vertical load $F$ as illustrated in Fig. 2. In this case, a vibration absorber can be represented as a single degree of freedom springmass-damper system.

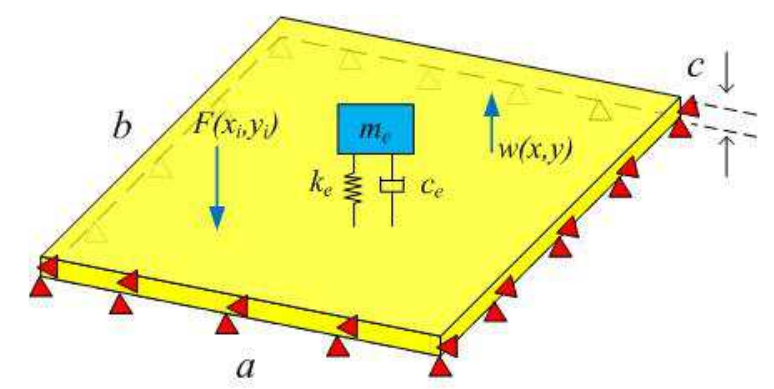

Fig. 2: Plate with attached vibration absorber

In order to calculate the response of plate attached with vibration absorber, the receptance at a point of attachment of absorber system is determined from Eq. 11.

$$
\beta_{22}=\frac{m_{e} s^{2}+c_{e} s+k_{e}}{m_{e} s^{2}\left(c_{e} s+k_{e}\right)}
$$

By manipulate Eqs.10 and 11, the response of a plate at point $\left(x_{1}, y_{1}\right)$ with a spring-mass-damper system attached at a point $\left(x_{2}, y_{2}\right)$ can be calculated using receptance method. The displacement equation for a plate with attached a vibration absorber is given as follows:

$$
w\left(x_{1}, y_{1}\right)=\left[\alpha_{11}-\frac{\alpha_{22}^{2}}{\alpha_{22}+\beta_{22}}\right] \cdot F\left(x_{i}, y_{i}\right)
$$

where,

$$
\begin{aligned}
& \alpha_{11}=\frac{1}{\rho a b c} \sum_{m=1}^{\infty} \sum_{n=1}^{\infty} \frac{\psi_{m n}^{2}\left(x_{1}, y_{1}\right)}{\omega_{m n}^{2}-\omega^{2}+j 2 \zeta \omega \omega_{m n}} \\
& \alpha_{21}=\frac{1}{\rho a b c} \sum_{m=1}^{\infty} \sum_{n=1}^{\infty} \frac{\psi_{m n}\left(x_{1}, y_{1}\right) \cdot \psi_{m n}\left(x_{2}, y_{2}\right)}{\omega_{m n}^{2}-\omega^{2}+j 2 \zeta \omega \omega_{m n}} \\
& \alpha_{22}=\frac{1}{\rho a b c} \sum_{m=1}^{\infty} \sum_{n=1}^{\infty} \frac{\psi_{m n}^{2}\left(x_{2}, y_{2}\right)}{\omega_{m n}^{2}-\omega^{2}+j 2 \zeta \omega \omega_{m n}}
\end{aligned}
$$




\section{Results and Discussion}

The displacement response of a fixed-fixed ends plate was plotted against frequency by using Matlab ${ }^{\circledR}$. The solution method that employed in this analysis was mode superposition method uses the natural frequencies and mode shapes from the modal analysis to characterize the dynamic response of a structure [11]. Table 1 describes the properties of the plate that used in the study.

Table 1. Properties of the plate

\begin{tabular}{ll}
\hline Properties & Value (unit) \\
\hline Geometry, $a \times b \times c$ & $1 \times 1 \times 0.01(\mathrm{~m})$ \\
Young's modulus, $E$ & $210(\mathrm{GPa})$ \\
Density, $\rho$ & $7850\left(\mathrm{~kg} / \mathrm{m}^{3}\right)$ \\
Poisson's ratio, $v$ & 0.3 (unit less) \\
\hline
\end{tabular}

Fig. 3 shows the magnitude and phase of the displacement response of the plate for the finite element analysis (FEA) and the mathematical model presented here, when no vibration absorber attached to the plate. For FEA, the result was obtained using Ansys ${ }^{\circledR}$ software. In order to obtain an accurate result, 400 modes were defined in Matlab ${ }^{\circledR}$ for the frequency range of 10 to $500 \mathrm{~Hz}$. The plate was subjected to a $1 \mathrm{~N}$ harmonic force.
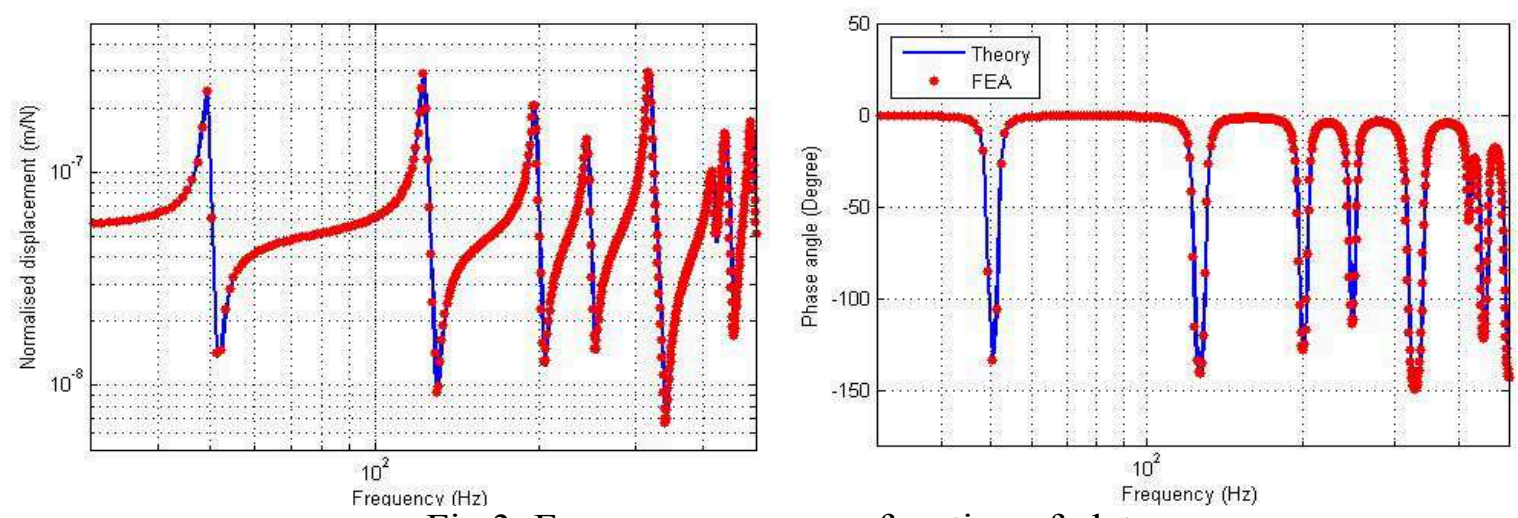

Fig 3. Frequency response function of plate
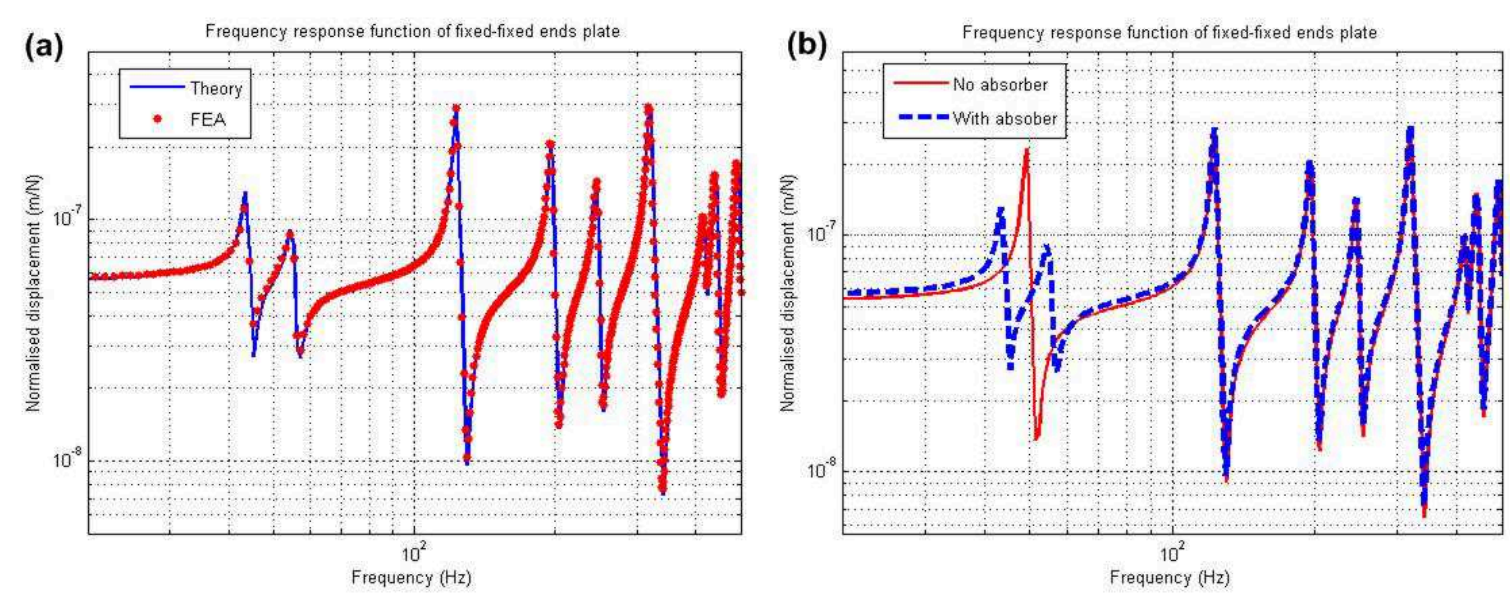

Fig. 4. Comparison of the receptance of plate with and without attached vibration absorber

From Fig. 3, it clearly shows that the derived theoretical equations which plotted using Matlab® is in good agreement with FEA result of Ansys ${ }^{\circledR}$. Fig. 4a shows the result of the frequency response function of the plate with attached a spring-mass-damper system obtained from Matlab ${ }^{\circledR}$ and Ansys ${ }^{\circledR}$. Again, both Matlab ${ }^{\circledR}$ and Ansys ${ }^{\circledR}$ show identical results for the frequency range of 10 to $500 \mathrm{~Hz}$. In this analysis, the spring stiffness is set to $95 \mathrm{kN} / \mathrm{m}$ in order to coincide with the first resonance frequency of the plate at $49 \mathrm{~Hz}$. Obviously, the displacement amplitude of plate dropped 
significantly when the vibration absorber tuned to the plate's first resonance frequency as depicted in Fig. 4b. Thus indicates the effectiveness of using vibration absorber to reduce the vibration response of plate at constant frequency. This result was found corroborates well with our previous study on the vibration absorber $[6,7,12]$.

\section{Conclusion}

A mathematical model was developed to enable the prediction vibration response of a fixed-fixed ends plate with a vibration absorber attached. In later stage, a comparison with finite element analysis was performed. It was found that both theoretical prediction and finite element analysis results were in good agreement, and the use of passive vibration is able to attenuate the vibration response of structure significantly.

\section{Acknowledgement}

IZ thanks Office for Research, Innovation, Commercialization and Consultancy Management and Universiti Tun Hussein Onn Malaysia for the financial support under Short Term Grant, vote 1332.

\section{References}

[1] C. Howard, Modal mass of clamped beams and clamped plates, Journal of Sound and Vibration 301 (2007) 410-414.

[2] M.S. Qatu, M.K. Abdelhamid, J. Pang, G. Sheng, Overview of automotive noise and vibration, International Journal of Vehicle Noise and Vibration 5 (2009) 135.

[3] I. Zaman, R.A. Rahman, H. Khalid, Dynamic analysis on off-road vechicle chassis using 3-d finite element model, Journal of Science and Technology 4 (2007) 1-16.

[4] I. Zaman, B. Manshoor, A. Khalid, S. Araby, M.I. Ghazali, Vibration characteristics of composite plate embedded with shape memory alloy at elevated temperature, Applied Mechanics and Materials 393 (2013) 655-660.

[5] I.Z. Bujang, M.K. Awang, A.E. Ismail. Study on the dynamic characteristic of coconut fibre reinforced composites. in Regional Conference on Engineering Mathematics, Mechanics, Manufacturing \& Architecture (EM ${ }^{3}$ ARC), 2007, Putrajaya, Malaysia.

[6] I. Zaman, M.M. Salleh, B. Manshoor, A. Khalid, S. Araby, The application of multiple vibration neutralizers for vibration control in aircraft, Applied Mechanics and Materials 629 (2014) 191-196.

[7] I. Zaman, M.M. Salleh, M. Ismon, B. Manshoor, A. Khalid, M.S.M. Sani, S. Araby, Study of passive vibration absorbers attached on beam structure, Applied Mechanics and Materials 660 (2014) 511-515.

[8] M.J. Brennan, Some recent developments in adaptive tuned vibration absorbers/neutraliser, Shock and Vibration 13 (2006) 531543.

[9] R.I. Wright, M.R.F. Kidner, Vibration absorbers: a review of applications in interior noise control of propeller aircraft, Journal of Vibration and Control 10 (2004) 1221-1237.

[10] C.R. Fuller, S.J. Elliott, Active control of noise and vibration, Academic Press, London, 1996.

[11] I. Zaman, A. Khalid, B. Manshoor, S. Araby, M.I. Ghazali, The effects of bolted joints on dynamic response of structures, IOP Conference Series: Materials Science and Engineering 50 (2013) 012018.

[12] I. Zaman, M.M. Salleh, M. Ismon, B. Manshoor, A. Khalid, M.S.M. Sani, S. Araby, Vibration attenuation of plate using multiple vibration absorbers, MATEC Web of Conferences 13 (2014) 03003. 